\title{
Relationship between Thoracic Kyphosis and Selected Cardiopulmonary Parameters and Respiratory Symptoms of Patients with Chronic Obstructive Pulmonary Disease and Asthma
}

\author{
Happiness Anulika Aweto, Rachel Ilojegbe Adodo \\ Department of Physiotherapy, Faculty of Clinical Sciences, College of Medicine, Lagos University, Nigeria
}

Background: Patients with advanced asthma and chronic obstructive pulmonary disease (COPD) have postural deviations such as thoracic hyperkyphosis, forward shoulder posture (FSP) due to an increase in head and cervical protraction, reduced shoulder range of motion and a corresponding increase in scapula elevation and upward rotation. Unlike congenital vertebral kyphosis that are permanent and rigid deformities with bony and other structural deformations which cause respiratory impairment, these deformities in these patients may be more flexible. Since the thoracic hyperkyphosis has been implicated as having adverse health consequences it is necessary to evaluated the relationship between thoracic kyphosis and cardiopulmonary functions of patients with COPD and asthma.

Methods: It was a cross-sectional analytical study. Eighty-four eligible patients with COPD and asthma were recruited from the Respiratory Unit, Department of Medicine, Lagos University Teaching Hospital (LUTH), and basic anthropometric parameters, pulmonary parameters, cardiovascular parameters, thoracic kyphosis (Cobb) angle and presence of respiratory symptoms of participants were assessed. Data was analyzed using SPSS version 20.

Results: There was no significant correlation between the thoracic kyphosis and selected pulmonary parameters (Forced Expiratory Volume in one second (FEV1, $p=0.36)$, Forced Vital Capacity $(F V C, p=0.95)$, Peak Expiratory Flow Rate (PEFR, $p=0.16)$, Thoracic expansion ( $T E$, $p=0.27$ )/cardiovascular parameters (Systolic Blood Pressure (SBP, $p=0.108$ ), Diastolic Blood Pressure (DBP, $p=0.17$ ) and Pulse Rate (PR, $p=0.93$ ) as well as the respiratory symptoms ( $S G R Q$ scores, $p=0.11$ ) in all subjects.

Conclusion: There was no relationship between thoracic kyphosis and selected pulmonary/cardiovascular parameters as well as respiratory symptoms in patients with COPD and asthma.

Keywords: Thoracic kyphosis, Chronic Obstructive Pulmonary Disease, Asthma, Cardiopulmonary, Respiratory Symptoms

\section{INTRODUCTION}

Chronic Obstructive Pulmonary Disease (COPD) is not one single disease but an umbrella term used to describe chronic lung diseases that cause limitations in lung airflow. 'The more familiar terms 'chronic bronchitis' and 'emphysema' are included within the COPD diagnosis. The most common symptoms of COPD are breathlessness, excessive sputum production, and a chronic cough. COPD is not just simply a "smoker's cough", but an under-diagnosed lung disease that may progressively lead to death. ${ }^{1}$
Asthma is a chronic inflammatory disorder of the respiratory airways, characterized by increased mucus production, airway hyper-responsiveness and variable airflow obstruction, that is often reversible spontaneously or following treatment. ${ }^{2}$ Worldwide, it is estimated that about 300 million individuals are affected with bronchial asthma, with 250,000 annual deaths attributed to the disease. ${ }^{2}$ In year 2000, 17.4\% of all deaths and 13.3\% of all Disability-Adjusted Life Years (DALYs) were attributed to asthma and four other respiratory diseases. ${ }^{3}$ In 2010, there were more than 230 million COPD cases among urban dwellers worldwide giving a prevalence rate of $13.6 \%$ and 153.7 million among rural dwellers giving a preva-

Copylight (C)2021 The Korean Society of Physical Therapy

This is an Open Access article distribute under the terms of the Creative Commons Attribution Non-commercial License (https:// creativecommons.org/license/by-nc/4.o.) which permits unrestricted non-commercial use, distribution, and reproduction in any medium, provided the original work is properly cited. 
lence rate of $9.7 \% .{ }^{4}$ The overall prevalence in men aged 30 years or more was $14.3 \%$ compared to $7.6 \%$ in women. ${ }^{4}$ The projection for 2030 indicates that COPD will be the third leading cause of death worldwide. ${ }^{1}$

Postural deviations such as thoracic hyperkyphosis and forward shoulder posture (FSP) (rounded shoulder posture) due to an increase in head and cervical protraction, reduced shoulder range of motion and a corresponding increase in scapula elevation and upward rotation are seen in patients with COPD. ${ }^{5-11}$ The increase in airway resistance and airflow limitation in these patients cause pulmonary hyperinflation, encouraging greater recruitment of the accessory muscles of respiration necessary to cope with the increased work of breathing. ${ }^{12}$ The hyperinflation forces the diaphragm to operate at non-optimal lengths while the increased load on the accessory respiratory muscles imposes limitations in upper limbbased functional tasks. ${ }^{13-15}$ The limitations in the upper limb use also contribute to increased respiratory muscle tightening, joint stiffness and increased work of breathing. ${ }^{15}$ The shortened respiratory muscle length and muscle weakness experienced by these patients lead to reduced chest expansion and reduced chest movements during respiration. ${ }^{12,16,17}$ There is reduction of thoracic mobility in all the three dimensions (anterior-posterior, superior-inferior and lateral dimensions) and this increases the effort of breathing resulting in stooping posture as a compensatory response in advanced stages of COPD. ${ }^{17,18}$ The increases in chest wall rigidity and respiratory muscle tightness may be linked to the postural deviations seen in COPD. ${ }^{7,19}$ Apart from shortening of the muscles of respiration, shortening of the pectoralis major muscle has also been implicated in forward shoulder posture assumed by these patients. ${ }^{20}$ Upper chest breathing in which the accessory muscles of respiration are utilized can also be found in bronchial asthma and this type of breathing leads to bronchial changes and musculoskeletal system dysfunction. ${ }^{21}$ The postural kyphosis observed in these patients are not as rigid as the more severe vertebral kyphosis such as the congenital type brought about by bony and other structural deformations that are permanent. Congenital thoracic kyphosis has been observed to cause respiratory impairment. ${ }^{22}$ This may be as result of the permanent bony and other structural deformations that limit lung expantion during inspiration. The resultant hypoxaemia and hypercapnia lead to an increase in the heart rate which negatively affects the cardiovascular system. ${ }^{23}$ This deformity also brings about other adverse consequences to health, such as negative affectation of the performance of daily activities, reduction in the quality of life and increase in the risk of mortality. ${ }^{5}$

Cobb angle is one of the measures used to measure spinal deformity. ${ }^{7,8,24,25}$ Originally, Cobb angle was used to determine lateral curve sever- ity in scoliosis but has subsequently been adapted to classify deformity in kyphosis. ${ }^{24,25}$ While a small amount of curvature of the thoracic spine is normal and present due to the shape of the vertebral bodies and intervertebral discs, a kyphosis (Cobb) angle greater than $40^{\circ}$, which is the 95th percentile of normal for young adults, is defined as hyperkyphosis. ${ }^{26,27} \mathrm{Ra}-$ diographic method is the most popular kyphosis measuring method. However, because it is expensive and exposes individuals to radiation, it is not the most appropriate method for periodic patient follow-up or for screening purposes. ${ }^{28}$ Results demonstrate that the Flexicurve method is equally reliable and valid to measure Cobb angle in order to determine the presence or absence of thoracic hyperkyphosis in an individual. ${ }^{5,29,30}$ It is a method of easy utilization in the clinical setting and in the context of human posture research. ${ }^{29}$ Chen et al. ${ }^{7}$ used chest CT scans to check for thoracic vertebral deformity in their subjects.

Since thoracic hyperkyphosis has been implicated as having adverse cardiopulmonary health consequences especially due to the limitation in expansion imposed on the lungs during inspiration by rigid bony and structural deformities in severe vertebral kyphosis, it is necessary to evaluate the relationship between thoracic kyphosis and selected pulmonary/ cardiovascular parameters as well as respiratory symptoms in patients with COPD and asthma.

\section{METHODS}

\section{Subjects}

Eighty-four patients with COPD and Asthma who were consecutively referred by their physicians from the Respiratory Unit, Department of Medicine, Lagos University Teaching Hospital (LUTH), Idi-Araba, Lagos state, Nigeria participated in this cross-sectional analytical study. Included into the study were patients diagnosed with COPD, patients diagnosed with asthma, patients with no other spinal deformity apart from kyphosis and patients who have not smoked for at least one year. This is because smoking could negatively affect the cardiopulmonary parameters and so influence the result of this study. Spinal deformity which includes thoracic kyphosis was assessed by physical examination and the use of flexicurve ruler. Excluded from the study were patients with other lung diseases such as lung cancer and tuberculosis, patients with sores or wounds around their chest wall and back. Ethical approval was sought and obtained prior to the study from the Health Research and Ethics Committee of Lagos University Teaching Hospital, Idi-Araba, Lagos state, Nigeria (Ref. No: CMUL/HREC/05/17/158). Written informed consent was obtained from 
each subject who participated in the study.

\section{Procedure for data collection}

The study was carried out at the out-patient clinic of the Respiratory unit of the Department of Medicine, Lagos University Teaching Hospital, Idi-Araba, Lagos state, Nigeria. Anthropometric measurements such as height and weight of eligible patients with COPD and asthma were taken using a heightmeter and a weighing scale respectivly. The singular assessments of the selected pulmonary parameters (Forced Expiratory Volume in one second $\left(\mathrm{FEV}_{\mathrm{l}}\right)$, Forced Vital Capacity (FVC), Peak Expiratory Flow Rate (PEFR)) were taken using a hand-held digital spirometer (CMS-SP 10, CONTEC, China) while the subject's chest wall expansion was measured with a tape-measure (in centimeters) placed at the level of the $\mathrm{Xi}$ phoid process, in the standing position. Chest expansion was calculated using the difference in chest wall circumference during the states of maximal expiration and maximal inspiration and the mean values of three measurements were taken. ${ }^{31-33}$ The cardiovascular parameters (Systolic Blood Pressure, SBP), Diastolic Blood Pressure (DBP) and Pulse Rate (PR)) were measured with a scphygmomanometer (Accoson, England) and stethoscope (Littmann).

The thoracic kyphosis (Cobb) angle was measured once using the flexicurve ruler. The flexicurve ruler is a strip of metal covered in plastic that allows one to measure the curves of the spine. It was placed on the back starting from the spinous process of the 7 th cervical vertebra $(\mathrm{C} 7)$ and gently moulded to that of the 12th thoracic vertebra (T12), reflecting the shape of the spine. These two land marks were previously marked on the subject's spine before measurement began. The moulded flexicurve ruler was then traced onto graph (millimeter) paper, marking C7 and T12 on the paper. A straight line connecting the two points that are equivalent to C7 and T12 was traced (X-total). Another straight but perpendicular line to the X-total known as the $\mathrm{H}$-line, was traced from a point on the X-total to the curve traced from the flexicurve ruler between C7 and T12. This Hline is the largest distance from the curve to the $\mathrm{X}$-total line. The X-middle is the distance between the T12 point and the point where $\mathrm{H}$-line touches the X-total line (Figure 1). After the X-total, X-middle and $\mathrm{H}$ distances had been determined in centimeters on the millimeter paper, the values were typed in a programme written on Microsoft Excel to calculate the thoracic kyphosis angle. ${ }^{29}$ The specific mathematical formula used is described as follows:

180/PI ()$^{*}\left(\operatorname{ATAN}\left(\mathrm{H}^{*} \mathrm{XTOTAL}{ }^{*}\left(-3^{*} \mathrm{XMIDDLE}+2^{*} \mathrm{XTOTAL}\right) / \mathrm{XMID}-\right.\right.$ DLE/(XTOTAL^2+XMIDDLE^2-2*XTOTAL ${ }^{\star}{ }^{\wedge}$ MIDDLE))-ATAN

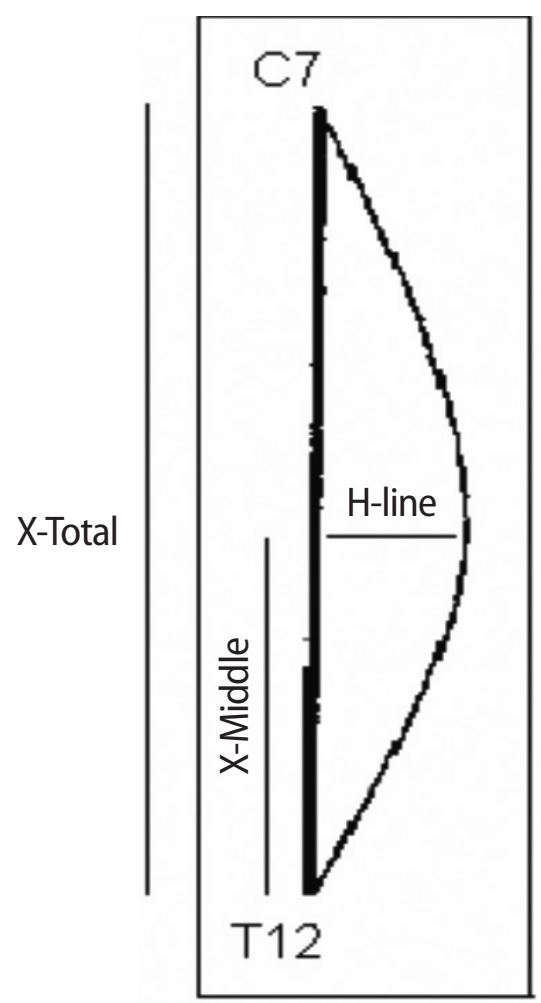

Figure 1. Illustration of X-total (distance between C7 and T12), X-middle (distance between $\mathrm{H}$ line and $\mathrm{T} 12$ ) and $\mathrm{H}$-line (distance between the X-total line and the vertex of the curve) measures from the Flexicurve method. ${ }^{29}$

\section{$\left(3^{*} \mathrm{H}^{\star}\left(\mathrm{XTOTAL}-2^{\star} \mathrm{XMIDDLE}\right) / \mathrm{XMIDDLE}{ }^{\wedge} 2 /\right.$}

$\left(\mathrm{XTOTAL}^{\wedge} 2+\mathrm{XMIDDLE}^{\wedge} 2-2^{*} \mathrm{XTOTAL}^{\star} \mathrm{XMIDDLE}^{\star} \mathrm{XTOTAL}^{\wedge} 2-2^{\star} \mathrm{H}^{\star}\right.$ $\left(\mathrm{XTOTAL}^{\wedge} 2-3^{*} \mathrm{XMIDDLE}^{\wedge} 2\right) / \mathrm{XMIDDLE}^{\wedge} 2 /\left(\mathrm{XTOTAL}^{\wedge} 2+\mathrm{XMIDDLE}^{\wedge} 2-\right.$ $\left.2^{\star} \mathrm{XTOTAL}^{\star} \mathrm{XMIDDLE}\right)^{\star} \mathrm{XTOTAL}+\mathrm{H}^{\star} \mathrm{XTOTAL}^{\star}\left(-3^{*} \mathrm{XMIDDLE}+\right.$ $2^{*} \mathrm{XTOTAL} / \mathrm{XMIDDLE} / \mathrm{XTOTAL}^{\wedge} 2+\mathrm{XMIDDLE}^{\wedge} 2-2^{*} \mathrm{XTOTAL}$ $\left.\left.{ }^{*} \mathrm{XMIDDLE}\right)\right)^{29}$

The respiratory symptoms were assessed using the St George's Respiratory Questionnaire (SGRQ). The SGRQ is a 50-item, self administered questionnaire developed to measure health status in patients with diseases of airways obstruction. ${ }^{34}$ Scores are calculated for three domains: Respiratory symptoms, Activity and Impacts (Psycho-social) as well as a total score. Psychometric testing has demonstrated its repeatability, reliability and validity. ${ }^{34}$ Sensitivity has been demonstrated in clinical trials. A minimum change in score of 4 units was established as clinically relevant after patient and clinician testing. The SGRQ has been used in a range of disease groups including asthma, COPD and bronchiectasis, and in a range of settings such as randomised controlled therapy trials and population surveys. ${ }^{35}$ 


\section{Statistical analysis}

Statistical Package for Social Sciences (SPSS) windows version 20 was used to analyze data. Descriptive statistics of mean and standard deviation were used to summarize data. Inferential statistics of Pearson's correlation coefficient was used to evaluate the relationship between the thoracic Cobb angle and the selected pulmonary/cardiovascular parameters as well as the respiratory symptoms of the subjects. The level of significance was set at $\mathrm{p}<0.05$.

\section{RESULTS}

A total of 84 subjects participated in the study. Thirty-eight (45.2\%) subjects were male and 46 (54.8\%) subjects were female.

\section{Anthropometric data of the subjects}

Table 1 shows the anthropometric data of the subjects. The mean age, weight and body mass index (BMI) of all the subjects were $26.8 \pm 14.2$ years, $67.5 \pm 10.9 \mathrm{~kg}$ and $23.4 \pm 3.7 \mathrm{~kg} / \mathrm{m}^{2}$ respectively. There were significant differences between the heights $(\mathrm{p}=0.001)$ and BMIs $(\mathrm{p}=0.01)$ of male and female subjects (Table 1).

Six (7.14\%) male subjects and 20 (23.81\%) female subjects were overweight. One (1.19\%) male subject and 1 (1.19\%) female subject were under- weight while 31 (36.90\%) male subjects and 25 (29.76\%) female subjects were normal weight.

The mean thoracic kyphosis (Cobb) angle was $41.03 \pm 1.29^{\circ}$. Thirteen (15.48\%) subjects had thoracic kyphosis (Cobb) angles that ranged from 31 to $40^{\circ}$ and $71(84.52 \%)$ subjects had thoracic kyphosis (Cobb) angles that ranged from 41 to $50^{\circ}$. There was no significant difference $(\mathrm{p}=0.25)$ between the mean values of the thoracic kyphosis (Cobb) angle for male and female subjects (Table 1).

\section{Comparison of the pulmonary and cardiovascular parameters across gender among the subjects}

The mean $\mathrm{FEV}_{1}$ values for male and female subjects were $2.49 \pm 0.96 \mathrm{~L}$ and $2.15 \pm 0.63 \mathrm{~L}$ respectively. The mean values of Thoracic Expansion (TE) for male and female subjects were $4.95 \pm 1.89 \mathrm{~cm}$ and $3.41 \pm 1.25 \mathrm{~cm}$ respectively (Table 2). The independent t-test analysis showed significant differences in the mean values of FVC $(\mathrm{p}=0.002)$ and TE $(\mathrm{p}=0.0001)$ between the male and the female subjects (Table 2). Concerning the cardiovascular parameters, the mean SBP value for male and the female subjects were $121.45 \pm 11.73 \mathrm{mmHg}$ and $117.98 \pm 12.03 \mathrm{mmHg}$ respectively. The mean value DBP for male and the female subjects were $80.58 \pm 9.55$ $\mathrm{mmHg}$ and $74.48 \pm 8.77 \mathrm{mmHg}$ respectively. The independent t-test analysis showed a significant difference between the male and the female sub-

Table 1. Anthropometric data of the subjects

\begin{tabular}{|c|c|c|c|c|c|}
\hline Variables & Males $(n=38)$ & Females $(n=46)$ & Total $(n=84)$ & t-test & p-value \\
\hline Age (yr) & $26.8 \pm 13.7$ & $26.7 \pm 14.8$ & $26.8 \pm 14.2$ & 0.23 & 0.98 \\
\hline Height (m) & $1.8 \pm 0.8$ & $1.6 \pm 0.8$ & $1.7 \pm 0.1$ & 7.45 & $0.001^{*}$ \\
\hline Weight (kg) & $69.9 \pm 10.5$ & $65.6 \pm 11.1$ & $67.5 \pm 10.9$ & 1.84 & 0.69 \\
\hline BMI $\left(\mathrm{kg} / \mathrm{m}^{2}\right)$ & $22.3 \pm 2.6$ & $24.3 \pm 2.7$ & $23.4 \pm 3.7$ & -2.59 & $0.01 *$ \\
\hline Thoracic Cobb angle $\left({ }^{\circ}\right.$ ) & $41.21 \pm 0.99$ & $40.88 \pm 1.48$ & $41.03 \pm 1.29$ & 1.168 & 0.25 \\
\hline
\end{tabular}

Mean \pm SD.

BMl: Body mass index.

${ }^{*} \mathrm{p}<0.05$.

Table 2. Comparison of the pulmonary and cardiovascular parameters across gender among the subjects

\begin{tabular}{|c|c|c|c|c|c|}
\hline Variables & Male $(n=38)$ & Female $(n=46)$ & All subjects $(n=84)$ & t-value & p-value \\
\hline $\mathrm{FEV}_{1}(\mathrm{~L})$ & $2.49 \pm 0.96$ & $2.15 \pm 0.63$ & $2.29 \pm 0.81$ & 1.77 & 0.86 \\
\hline FVC (L) & $3.19 \pm 0.78$ & $2.75 \pm 0.92$ & $2.95 \pm 0.88$ & 3.32 & $0.002^{*}$ \\
\hline PEFR (L) & $5.82 \pm 2.49$ & $5.20 \pm 1.98$ & $5.48 \pm 2.23$ & 0.58 & 0.57 \\
\hline $\mathrm{TE}(\mathrm{cm})$ & $4.95 \pm 1.89$ & $3.41 \pm 1.25$ & $4.11 \pm 1.75$ & 4.45 & 0.0001 * \\
\hline $\mathrm{SBP}(\mathrm{mmHg})$ & $121.45 \pm 11.73$ & $115.11 \pm 11.63$ & $117.98 \pm 12.03$ & 0.15 & 2.48 \\
\hline $\mathrm{DBP}(\mathrm{mmHg})$ & $80.58 \pm 9.55$ & $74.48 \pm 8.77$ & $77.24 \pm 9.57$ & 3.05 & $0.03^{*}$ \\
\hline PR (bpm) & $80.32 \pm 14.65$ & $81.72 \pm 11.10$ & $81.08 \pm 10.23$ & -0.49 & 0.62 \\
\hline
\end{tabular}

Mean \pm SD.

FEV1: Forced expiratory volume in 1 second, FVC: Forced vital capacity, PEFR: Peak expiratory flow rate, TE: thoracic expansion, SBP: Systolic blood pressure, DBP: Diastolic blood pressure, PR: Pulse rate.

${ }^{*} p<0.05$. 
jects' mean values of $\mathrm{DBP}(\mathrm{p}=0.03)$ (Table 2$)$.

\section{Comparison of the mean SGRQ scores (respiratory symptoms) across gender among the subjects}

Table 3 shows a comparison of the mean SGRQ scores across gender among the subjects.

The mean SGRQ scores for the male and the female subjects were 32.48 \pm 16.27 and $37.42 \pm 16.09$ respectively. The independent $t$-test analysis showed no significant difference between the male and the female subjects' mean scores of SGRQ $(\mathrm{p}=0.17)$ (Table 3$)$.

\section{Relationship between the thoracic kyphosis (Cobb) angle and pulmonary function parameters of all subjects and within gender}

Table 4 shows the relationship between the thoracic kyphosis (Cobb) angle and pulmonary function parameters of all subjects and within gender. The results of the analysis using the Pearson's correlation coefficient showed that there was no significant correlation between the thoracic kyphosis (Cobb) angle and the pulmonary function parameters in all the

Table 3. Comparison of the SGRQ scores (respiratory symptoms) across gender among the subjects

\begin{tabular}{lccccc}
\hline Variables & $\begin{array}{c}\text { Male } \\
(n=38)\end{array}$ & $\begin{array}{c}\text { Female } \\
(n=46)\end{array}$ & $\begin{array}{c}\text { All subjects } \\
(n=84)\end{array}$ & t-value & $p$-value \\
\hline
\end{tabular}

\begin{tabular}{llllll}
\hline SGRQ score & $32.48 \pm 16.27$ & $37.42 \pm 16.09$ & $35.18 \pm 16.27$ & -1.39 & 0.17
\end{tabular}

Mean \pm SD.

SGRQ: St george's respiratory questionnaire.

Table 4. Relationship between the thoracic kyphosis (Cobb) angle and pulmonary function parameters of all subjects and within gender

\begin{tabular}{lccccc}
\hline Variables & & FEV $_{1}$ & FVC & PEFR & TE \\
\hline All subjects & & & & & \\
Thoracic Cobb angle & $r$ & 0.101 & -0.07 & 0.15 & 0.12 \\
& $p$ & 0.36 & 0.95 & 0.16 & 0.27 \\
Male subjects & & & & & \\
Thoracic Cobb angle & $r$ & 0.25 & 0.82 & 0.23 & 0.96 \\
& $p$ & 0.13 & 0.62 & 0.17 & 0.57 \\
Female subjects & & & & & \\
Thoracic Cobb angle & $r$ & -0.64 & -0.14 & 0.88 & 0.64 \\
& $p$ & 0.67 & 0.35 & 0.56 & 0.67 \\
\hline
\end{tabular}

FEV1: Forced expiratory volume in 1 second, FVC: Forced vital capacity, PEFR: Peak expiratory flow rate, TE: Thoracic expansion, r: Correlation coefficient.

${ }^{*} p<0.05$.

Correlation Guide

0.00-0.19: Very weak.

0.20-0.39: Weak

0.40-0.59: Moderate.

0.60-0.79: Strong.

0.80-1.0: Very strong. ${ }^{43}$ subjects $(\mathrm{p}>0.05)$ (Table 4$)$.

\section{Relationship between the thoracic kyphosis (Cobb) angle and cardiovascular parameters of all the subjects and within gender}

Table 5 shows the relationship between thoracic kyphosis (Cobb) angle and cardiovascular parameters of all the subjects and within gender. The results of the analysis using the Pearson's correlation coefficient showed that there was no significant correlation between the thoracic kyphosis (Cobb) angle and the cardiovascular parameters in all subjects ( $\mathrm{p}>0.05$ ). However, there was a weak significant correlation between the thoracic kyphosis (Cobb) angle and DBP in the female subjects $(\mathrm{p}=0.04)$ (Table 5).

\section{Relationship between the thoracic kyphosis (Cobb) angle and SGRQ scores of all the subjects and within gender}

Table 6 shows the relationship between thoracic kyphosis (Cobb) angle and SGRQ scores of all subjects and within gender. The results of the analysis using the Pearson's correlation coefficient showed that there was no significant correlation between the thoracic kyphosis (Cobb) angle and the SGRQ scores in all subjects ( $\mathrm{p}>0.05$ ) (Table 6).

\section{DISCUSSION}

The purpose of this study was to determine the relationship between thoracic kyphosis (Cobb) angle and selected pulmonary parameters

Table 5. Relationship between the thoracic kyphosis (Cobb) angle and cardiovascular parameters of all the subjects and within gender

\begin{tabular}{lcccc}
\hline Variables & & SBP & DBP & PR \\
\hline All subjects & & & & \\
& $r$ & 0.18 & 0.15 & 0.101 \\
& $\mathrm{p}$ & 0.11 & 0.17 & 0.93 \\
Male subjects & & & & \\
Thoracic Cobb angle & $\mathrm{r}$ & 0.44 & -0.18 & 0.601 \\
& $\mathrm{p}$ & 0.79 & 0.23 & 0.72 \\
Female subjects & & & & \\
Thoracic Cobb angle & $\mathrm{r}$ & 0.21 & 0.306 & -0.01 \\
& $\mathrm{p}$ & 0.16 & $0.04^{*}$ & 0.94 \\
\hline
\end{tabular}

SBP: Systolic blood pressure, DBP: Diastolic blood pressure, PR: Pulse rate, r: Correlation coefficient.

${ }^{*} \mathrm{p}<0.01$.

Correlation Guide

0.00-0.19: Very weak

0.20-0.39: Weak

0.40-0.59: Moderate.

0.60-0.79: Strong.

0.80-1.0: Very strong. ${ }^{43}$ 
Table 6. Relationship between the thoracic kyphosis (Cobb) angle and SGRQ scores (respiratory symptoms) of all the subjects and within gender

\begin{tabular}{lcc}
\hline Variables & & SGRQ scores \\
\hline All subjects & $r$ & 0.17 \\
Thoracic Cobb angle & $p$ & 0.11 \\
& & \\
Male subjects & $r$ & -0.27 \\
Thoracic Cobb angle & $p$ & 0.87 \\
Female subjects & & \\
Thoracic Cobb angle & $r$ & 0.33 \\
& $p$ & 0.26 \\
\hline
\end{tabular}

SGRQ: St george's respiratory questionnaire, r: Correlation coefficient. Correlation Guide

0.00-0.19: Very weak.

0.20-0.39: Weak

0.40-0.59: Moderate.

$0.60-0.79$ : Strong.

0.80-1.0: Very strong. ${ }^{43}$

(FEV1, FVC, PEFR, and TE), cardiovascular parameters (SBP, DBP, and PR) and respiratory symptoms of patients with COPD and Asthma. There was no significant correlation between the thoracic kyphosis (Cobb) angle and the pulmonary function parameters, cardiovascular parameters and respiratory symptoms respectively.

A thoracic kyphosis angle greater than 40 degree, which is the 95th percentile of normal for young adults, is defined as hyperkyphosis. ${ }^{26}$ The results from this study showed that a high number of the subjects (84.52\%) had a thoracic kyphosis (Cobb) angle which was greater than $40^{\circ}$ (hyperkyphosis). This is due to the postural deviations (thoracic hyperkyphosis) which many of the patients with chronic obstructive lung diseases tend to assume..$^{5-7}$ The finding that $85.19 \%$ of all the subjects with asthma had hyperkyphosis highlighted that there may be high prevalence of thoracic hyperkyphosis among patients with asthma.

The finding that there was no significant difference between the mean values of the thoracic kyphosis (Cobb) angle of male and female subjects may imply that gender had no influence on the thoracic kyphosis (Cobb) angles of these patients. Fon et $\mathrm{al}^{26}$ showed that the mean Cobb angle for female exceeded that of the male healthy individuals with an increase in age. This difference in findings of the two studies may be as a result of the differences in the health status and age of the subjects involved in the two studies.

The result of the correlation between thoracic kyphosis (Cobb) angle and the pulmonary parameters showed no significant correlation. This implies that thoracic kyphosis (Cobb) angle of individuals with COPD and asthma does not have any effect on their pulmonary parameters and cannot be used as a determinant for them. However, a previous study showed a significant negative correlation between kyphosis angle and inspiratory capacity, vital capacity, as well as thoracic expansion in normal women and women with osteoporosis. ${ }^{36}$ Lung volumes and rib mobility were significantly impaired in normal women with thoracic kyphosis. ${ }^{36}$ The more thoracic flexion or kyphosis an individual has, the less their lung capacity. Lung capacity can decrease by as much as 30\% in these individuals. ${ }^{37}$ Joehaimey et al..$^{38}$ also showed that lung function impairment was seen in more severe spinal deformities of adolescent idiopathic scoliosis patients with proximally-located curvatures. McMaster et al. ${ }^{22} \mathrm{ob}$ served that $54 \%$ of patients with congenital vertebral kyphosis had respiratory impairment in various degrees. This may be as a result of the congenital origin of the kyphosis and kyphoscoliosis which are permanent deformities. They stated that kyphosis at the higher level of the vertebrae especially those above T10 had greater effect on respiratory impairment.

The result of the relationship between thoracic kyphosis (Cobb) angle and the cardiovascular parameters showed no significant correlation for all subjects. This implies that thoracic kyphosis (Cobb) angle of individuals with COPD and asthma does not have any effect on their cardiovascular parameters and cannot be used as a determinant for them. The weak significant correlation between thoracic kyphosis (Cobb) angle and DBP among the female subjects may imply that thoracic kyphosis (Cobb) angle of female individuals with COPD and asthma affects their DBP. Nishiwaki et al. ${ }^{39}$ showed that thoracic kyphosis is associated with subjective poor health but not associated with functional activity and blood pressure in both males and females community-dwelling elderly. In the selection of this elderly population into the study, the authors' inclusion criteria was being age 65 and above and not having COPD or asthma.

The result of the relationship between thoracic kyphosis (Cobb) angle and the respiratory symptoms showed no significant correlation. This implies that thoracic kyphosis (Cobb) angle of individuals with COPD and asthma does not have any effect on their respiratory symptoms and cannot be used as a determinant for them.

In summary, the increased thoracic kyphosis (Cobb) angle observed among most of the patients with COPD and asthma and the non-significant correlation between the thoracic kyphosis (Cobb) angle and the cardiopulmonary parameters of these patients may be explained by the fact that the thoracic hyperkyphosis of patients with COPD and asthma is a flexible postural deformity acquired as a coping strategy to improve pulmonary functions rather than being the cause of the worsening cardiopulmonary functions of these patients. Gaude et al. ${ }^{40}$ reported that the 
postural thoracic kyphosis in patients with COPD is a flexible deformity. Donrawee et al. ${ }^{17}$ reported that the stooping posture adopted by patients in advanced stages of chronic lung diseases is a compensatory response to improve ventilation in these conditions. Forward lean posture is one of the treatment procedures utilized by physiotherapists in the management of dyspnea in patients with chronic respiatory diseases. ${ }^{41}$ However some other authors reported that there may be a more permanent damage such as vertebrae compression fracture, osteoporosis-related vertebral deformity and misalignment of joints between the ribs and vertebrae in patients with COPD.,42

\section{REFERENCES}

1. World Health Organization. Chronic Respiratory Diseases [Internet]. 2016 [cited 2016 August 28]. Available from: www.who.int.

2. Global Initiative for Asthma (GINA). Global strategy for asthma management and prevention [Internet]. 2012 [cited 2015 September 10]. Available from: http://www.ginasthma.org.

3. World Health Organization. WHO Strategy for prevention and control of chronic respiratory disease [Internet]. 2002 [cited 2017 August 06]. Available from: http://whglibdoc.who.int/hq/2002/WHO_MNC_ CRA_02.1.pdf.

4. Adeloye D, Chua S, Lee C et al. Global and regional estimates of COPD prevalence: sytematic review and meta-analysis. J Glob Health. 2015; 5(2):020415.

5. Goncalves MA, Rodovalho PL, Bellini AJ et al. Thoracic kyphosis comparison between a patient with COPD and a healthy individual by flexicurve method. Fisioter Pesqui. 2015;22(3):333-9.

6. Kjensli A, Falch J, Ryg M et al. High prevalence of vertebral deformities in COPD patients: relationship to disease severity. Eur Respir J. 2009; 33(5):1018-24.

7. Chen YW, Coxson H, Coupal T et al. The contribution of thoracic vertebral deformity and arthropathy to trunk pain in patients with chronic obstructive pulmonary disease (COPD). Respir Med. 2018;137:115-22.

8. Lee AL, Goldstein RS, Chan C et al. Postural abnormalities in people with chronic obstructive pulmonary disease. Can J Respir Crit Care Sleep Med. 2018;2:61-8.

9. Kaneko H, Shiranita S, Horie J et al. Reduced chest and abdominal wall mobility and their relationship to lung function, respiratory muscle strength and exercise tolerance in subjects with COPD. Respir Care. 2016;61(11):1472-80.

10. Morais N, Cruz J, Marques A. Posture and mobility of the upper body quadrant and pulmonary function in COPD: an exploratory study. Braz J Phys Ther. 2016;20:345-54.

11. Dias D, Kirkwood R, Parreira V et al. Orientation and position of the scapula, head and thoracic kyphosis in male patients with COPD. Can J Respir Ther. 2009;45(2):30-4.

12. Clarke S, Munro PE, Lee AL. The role of manual therapy in patients with COPD. Healthcare. 2019;7(1):21.

13. Papandrinopoulou D, Tzouda V, Tsoukalas G. Lung compliance and chronic obstructive pulmonary disease. Pulm Med. 2012;2012:542769.

14. Donaldson A, Maddocks M, Martolini D et al. Muscle function in COPD: a complex interplay. Int J Chronic Obstr Pulm Dis. 2012;7:52335.

15. Putt M, Watson M, Seale HE et al. Muscle stretching technique increases vital capacity and range of motion in patients with chronic obstructive pulmonary disease. Arch Phys Med Rehabil. 2008;89(6):110307.

16. Duranti R, Misuri G, Gorini M et al. Mechanical loading and control of breathing in patients with severe chronic obstructive pulmonary disease. Thorax. 1995;50(2):127-33.

17. Donrawee L. Chest mobilization techniques for improving ventilation and gas exchange in chronic lung disease. Chronic Obstruct Pulm Dis Curr Concepts Pract. 2012:400.

18. Tattersall R, Walshaw M. Posture and cystic fibrosis. J R Soc Med. 2003; 96(S43):18.

19. Chen YW, Camp P, Coxson H et al. Comorbidities that cause pain and the contributors to pain in individuals with chronic obstructive pulmonary disease. Arch Phys Med Rehabil. 2017;98(8):153543.

20. Ghanbari A, Ghaffannejad H, Mohammad F et al. Effect of forward shoulder posture on pulmonary capacities of women. Br J Sports Med 2008;42(7):622-3.

21. Katerina, Jakub, Jana et al. Chest expansion in preschool-age children with mild bronchial asthma. Eur Respiratory Soc. 2012;40:1198.

22. McMaster MJ, Glasby MA, Singh $\mathrm{H}$ et al. Lung function in congenital kyphosis and kyphoscoliosis. Clin Spine Surg. 2007;20(3):203-8.

23. Rabe KF, Hurd S, Anzueto A et al. Global strategy for the diagnosis, management, and prevention of chronic obstructive pulmonary disease: GOLD executive summary. Am J Respir Crit Care Med. 2007;176(6): 532-55.

24. Singh S, Puhan MA, Andrianopoulos V et al. An official systematic review of the european respiratory society/american thoracic society: measurement properties of field walking tests in chronic respiratory disease. Eur Respir J. 2014;44(6):1447-78.

25. Lee AL, Zabjek K, Goldstein RS et al. Systematic review of postural assessment in individuals with obstructive respiratory conditions-Measurement and clinical associations. J Cardiopulm Rehabil Prev. 2017; 37(2):90-102.

26. Fon GT, Pitt MJ, Thies JR et al. Thoracic kyphosis: range in normal subjects. Am J Roentgenol. 1980;134(5):979-83.

27. Katzman WB, Wanek L, Shepherd JA et al. Age-related hyperkyphosis: its causes, consequences and management. J Orthop Sports Phys Ther. 2010;40(6):352-60.

28. Wilner S. Spinal pantograph - a non-invasive technique for describing kyphosis and lordosis in the thoraco-lumbar spine. Acta Orthop Scand. 1981;52(5):525-9.

29. Teixeira FA, Carvalho GA. Reliability and validity of thoracic kyphosis measurements using the flexicurve method. Braz J Phys Ther. 2007;11 (3):173-7.

30. Lee AL, Goldstein RS, Rhim M et al. Reliability and validity of non-radiological measures of thoracic kyphosis in chronic obstructive pulmonary disease. Int J Ther Rehabil. 2018;25(12):648-54.

31. Minoguchi H, Shibuya M, Tetsuo M et al. Cross-over comparison between respiratory muscle stretch gymnastics and inspiratory muscle training. Intern Med. 2002;41(10):805-12. 
32. Kim KS, Byun MK, Lee WH et al. Effects of breathing maneouver and sitting posture on muscle activity in inspiratory accessory muscles in patients with chronic obstructive pulmonary disease. Multidiscip Respir Med. 2012;7(1):1-6.

33. Jung JH, Moon DC. The effect of thoracic region self-mobilization on chest expansion and pulmonary function. J Phys Ther Sci. 2015;27(9): 2779-81.

34. Jones PW, Quirck FH, Baveystock CM. The st george's respiratory questionnaire. Respir Med. 1991;85:25-31.

35. Aweto HA, Aiyegbusi AI, Ugonabo AJ et al. Effects of aerobic exercise on the pulmonary functions, respiratory symptoms and psychological status of people living with HIV. J Res Health Sci. 2016;16(1):17-21.

36. Culham EG, Jimenez HA, King CE. Thoracic kyphosis, rib mobility and lung volumes in normal women and women with osteoporosis. Spine. 1994;19(11):1250-5.

37. Whitehead M. How posture affects lung capacity [Internet]. 2015 [cited 2017, August 8]. Available from: www.oregonexercisetherapy.com.

38. Joehaimey J, Mohd AS, Azriani AR et al. Relationship between Pulmonary Function and degree of spinal deformity, location of apical verte- brae and age among adolescent idiopathic scoliosis patients. Singapore Med J. 2016;57(1):33.

39. Nishiwaki Y, Kikuchi Y, Araya K et al. Association of thoracic kyphosis with subjective poor health, functional activity and blood pressure in the community-dwelling elderly. Environ Health Prev Med. 2007;12(6): 246-50.

40. Gaude GS, Saradatti R, Hattihali J. Postural correction for kyphosis improves dyspnea index and pulmonary functions of patients with COPD: a randomized trial over 12weeks. Int J Health Allied Sci. 2014;3(1):4451.

41. Bott J, Blunenthal S, Buxton M et al. Guidelines for physiotherapy management of adult, medical and spontaneously breathing patients. Thorax. 2009;64(S1):1-52.

42. Reid WD, Chen YW, Coxson H. Vertebral deformity and hyperkyphosis in people with chronic obstructive pulmonary disease. Eur Respir J. 2016;48:PA3765.

43. Evans J, St BT, Over DE. Rationality and reasoning. London, Psychology Press, 1996 